\title{
Access to credit and determinants of technical inefficiency of specialized smallholder farmers in Chile
}

\author{
Stephan von Cramon-Taubadel ${ }^{1}$, and Rodrigo Saldias ${ }^{2 *}$
}

\begin{abstract}
Access to credit and credit constraint are critical determinants of competitiveness in agriculture; they have an impact on the technical efficiency of farms. The objective of this study was to analyze how credit variables influence the technical efficiency of two groups of specialized smallholder farmers in Chile. The translog stochastic production frontier model was used to predict the level of farm technical efficiency by the maximum likelihood method. Based on 2004 data, production functions and technical inefficiency score were estimated for 109 livestock and 342 crop producers. Results showed that the mean technical efficiency was $89 \%$ and $78 \%$ for crop and livestock producers, respectively. Technical efficiency increased with the decreasing use of inputs, dependence on on-farm income, farmer education, family size, and age of the head of household. Credit volume had a significant impact by increasing and decreasing efficiency in crop and livestock production, respectively. Correspondingly, credit-constrained farmers were less efficient in crop production and more efficient in livestock production. For livestock producers, credit volume and credit constraints were found to be endogenous to technical efficiency. A possible explanation is the organization of public support for small livestock producers in Chile, which provides lenders with information about individual livestock producers. Correcting for this endogeneity did not lead to qualitatively different results, but it did influence point estimates of parameters in the production function and inefficiency models, suggesting that it is important to test for endogeneity in the variables used to model inefficiency effects.
\end{abstract}

Key words: Credit, credit constrained, endogeneity, small farmer, stochastic frontier, technical inefficiency.

\section{INTRODUCTION}

Since Chile opened its economy at the end of the 1970s, the agricultural sector has experienced rapid growth and changes in land use. Driven by export demand, production of fruit, vegetables, and forestry products has increased in relation to livestock and field crop production. Today, Chilean agriculture is perceived abroad as being dominated by large export-oriented farms producing fruit, vegetables, and wine. However, Chilean domestic policy is also concerned for over 278000 small farms. These operate on an average of 14 ha each, account for $85 \%$ of all farms, and use over $40 \%$ of the area dedicated to crop, vegetable, grape production, dairy cows, and beef cattle in Chile.

Financing of Chilean agriculture is mainly based on private sector funds, such as farmers' own resources, formal and informal capital markets, and loans from

\footnotetext{
${ }^{1}$ University of Göttingen, Department for Agricultural Economics and Rural Development, Platz der Göttinger Sieben 5 D-37073, Göttingen, Germany.

${ }^{2}$ Universidad Central de Chile, Facultad de Ciencias Económicas y Administrativas, Lord Cochrane 417 Torre A, Santiago, Chile.

*Corresponding author (rsaldiasq@ucentral.cl).

Received: 30 March 2014.

Accepted: 29 July 2014.
}

doi:10.4067/S0718-58392014000400006 agribusiness firms and export companies; however, the public institution INDAP (Instituto de Desarrollo Agropecuario) provides credit to a large number of small farmers who have difficulty securing loans in formal credit markets. Discussions with lenders suggest that it is more difficult to establish creditworthiness in livestock than in crop production because livestock producers tend to have less collateral and weaker relationships with up- and downstream agribusiness, and the relationship between credit use and improvements in profitability is more tenuous and slower to unfold in livestock production. However, the main providers of credit to agriculture are INDAP and the public bank Banco Estado had responded by designing special credit channels for livestock producers at the time of the sample.

Little is known about the impact of credit access on the efficiency of small farms. The relationship between credit and technical efficiency is complex and ambiguous. Theoretical explanations for both positive and negative impact have been proposed (Nasr et al., 1998; Hadley et al., 2001; Lambert and Bayda, 2005; Davidova and Latruffe, 2007; Ayaz and Hussain, 2011). Explanations that point to positive impact include the theory of credit evaluation in which lenders can partly base their credit evaluation on a firm's performance. In this case, there is a positive correlation between credit and technical efficiency because inefficient firms are less likely to receive credit. Of course, this explanation reverses the direction of causality 
from credit to efficiency and raises the possibility of endogeneity in econometric analysis. The free cash flow theory states that large asset holdings and excess cash flow can encourage a lack of discipline in management, which leads to technical inefficiency compared with a situation in which a firm depends on credit. This theory is presumably limited in its applicability to smallholder agriculture in a setting such as Chile. The embodied capital approach stresses the importance of credit as a means of investing to 'keep up' with the production frontier as it shifts upwards over time and thus maintain or improve efficiency. On the other hand, explanations for a negative relationship between credit and technical efficiency include the agency cost theory which affirms that lenders deal with the asymmetric distribution of information between themselves and borrowers by transferring higher costs to borrowers such as higher interest rates or higher collateral requirements. All other things being equal, more indebted farmers therefore bear higher costs and are less efficient. The theory of adjustment proposes that firms undergoing adjustment, for example, due to trade liberalization, are forced to be more efficient in order to survive, but that ability to adjust is negatively related to indebtedness. Farms with lower credit burdens are able to adjust more easily and are thus more efficient.

Most studies analyze the impact of the debt-asset ratio on technical efficiency. These studies reach varied conclusions and some find a significant positive impact of credit on technical efficiency, while others a significant negative impact (Binam et al., 2004; Karagiannis and Sarris, 2005; Hadley, 2006; Onwuchekwa, 2008; Ziaul et al., 2011). No studies simultaneously consider the impact of credit constraints and credit volumes on technical efficiency. We propose considering both credit volumes and credit constraints because these two dimensions of a farm's credit situation might affect efficiency in different ways (e.g., the agency cost theory is especially relevant for farms with large credit volumes, while the theory of adjustment especially applies to credit-constrained farms), and these might interact (e.g., the impact of a given volume of credit differs according to whether the farm is credit constrained or not).

Literature is limited as to the possible endogeneity of access to credit in studies of its impact on technical efficiency. As mentioned above, the credit evaluation theory suggests that more efficient farms have easier access to credit because they are perceived as being more creditworthy by lenders. If this is true, estimates of the impact of credit on efficiency suffer from simultaneous equation bias.

The purpose of this study was to shed light on the impact of credit on the technical efficiency of specialized smallholder crop and livestock farms in Chile. By using detailed 2004 cross-section data, we addressed the following questions: Does access to credit influence technical efficiency? How does credit constraint affect technical efficiency? Do the answers to these questions differ between smallholders specializing in crop production and those specializing in livestock?

\section{MATERIALS AND METHODS}

We followed a parametric approach known as stochastic frontier analysis. This approach explicitly allows for measurement error as well as random factors that are not under a farmer's control, such as weather and disease. It also makes it possible to test hypotheses about a farm's production technology and impose corresponding restrictions. Stochastic frontier techniques are wellestablished in the literature. A simple representation of the stochastic frontier model is:

$$
\mathrm{y}_{\mathrm{i}}=\mathrm{f}\left(\mathrm{x}_{\mathrm{i}}\right) \exp \left(\mathrm{w}_{\mathrm{i}}\right)
$$

where $y_{i}$ denotes the level of output for observation $i$ (farm), $x_{i}$ is a vector of $k$ input levels for that farm, $f(\cdot)$ is the frontier production function, and $w_{i}=v_{i}-u_{i}$ is a composite error. The error component $v_{i}$ is a pure random (white noise) component that accounts for factors that are beyond the farmers' control, such as weather, as well as omitted variables and measurement error; $u_{i}$ is a systematic, nonnegative component that accounts for inefficiency. The corresponding output-oriented technical efficiency measure, $T E_{i}=\exp \left(-u_{i}\right) \in[0,1]$, indicates how much farm $i$ could increase its output given the technology and input levels it uses. An output-oriented approach is appropriate in agricultural settings because input choices are made at the beginning of the production period and input levels can therefore be considered predetermined (Griliches, 1963). In this case, there is no correlation between the stochastic error and the predetermined input variables in the production function, and direct estimation of Equation [1] does not suffer from simultaneous equation bias (Zellner et al., 1966). Given that only $w_{i}$ is observed, distributional assumptions for $v_{i}$ and $u_{i}$ must be made. It is assumed in most applications that $v_{i}$ follows a normal distribution, $u_{i}$ follows a half-normal distribution, and $\operatorname{cov}\left(v_{i}, u_{i}\right)=0$.

Based on this model, many empirical analyses have been two-stepped. The stochastic frontier model is estimated in the first step, and in the second step, estimated $T E_{i}$ is regressed on a vector of variables $z_{i}$ (that can overlap with $x_{i}$ ) that are hypothesized to explain differences in efficiency across farms. However, it can be demonstrated (Caudill and Ford, 1993; Wang and Schmidt, 2002) that this procedure leads to biased estimators. An alternative, based on pioneering papers by Huang and Liu (1994) and Battese and Coelli (1995), is to estimate a full model by

$$
\mathrm{y}_{\mathrm{i}}=\mathrm{f}\left(\mathrm{x}_{\mathrm{i}}\right) \exp \left(\mathrm{v}_{\mathrm{i}}-\mathrm{u}_{\mathrm{i}}\left(\mathrm{z}_{\mathrm{i}}\right)\right)
$$

in one step using maximum likelihood methods. We followed this approach by using a translog specification of Equation [2]:

$\ln \left(\mathrm{y}_{\mathrm{i}}\right)=\beta_{0}+\Sigma \beta_{\mathrm{k}} \ln \left(\mathrm{x}_{\mathrm{ki}}\right)+0.5 \Sigma \Sigma \beta_{\mathrm{lp}} \ln \left(\mathrm{x}_{\mathrm{li}}\right) \ln \left(\mathrm{x}_{\mathrm{pi}}\right)+\mathrm{v}_{\mathrm{i}}-\mathrm{u}_{\mathrm{i}}[3]$ with the following assumptions and modifications: 
symmetry was assumed $\left(\beta_{l p}=\beta_{p l}\right), v_{i}$ was assumed to be an independent and identically distributed (iid) normal random variable with constant variance $\sigma_{v}^{2}$; following Caudill et al. (1995) and Brümmer and Loy (2000), systematic deviations from the frontier $u_{i}$ were assumed to be iid half-normal random disturbances uncorrelated with $v$ with mean zero and a heteroscedastic (i.e., farmspecific) variance $\sigma_{u i}{ }^{2}$ such that $\ln \left(\sigma_{u i}{ }^{2}\right)=\sigma_{0}+\Sigma \phi_{j} z_{j}+\xi_{i}$ where $\phi_{j}$ were parameters to be estimated that measured the influence of variables in $z$ on efficiency, and $\xi_{i}$ was assumed to be an iid normal random disturbance.

Given that inefficiency was modeled in Equation [3], a negative coefficient indicated that the variable being considered reduced inefficiency or increased efficiency. The specification used allowed us to interpret the individual coefficients in the inefficiency model as the marginal effects of the corresponding variables.

The dependent variable $y_{i}$ used to estimate Equation [3] was defined as farm income measured in thousands of Chilean pesos (CLP). The vector $x$ consisted of four inputs: land ( $L$, in ha), working capital (WC, in thousands of CLP) as a proxy for intermediate inputs, the market value of livestock ( $\mathrm{AV}$, in thousands of CLP) evaluated at sample mean as a proxy for capital stock, and estimated labor input $\left(\mathrm{T}\right.$, in $\mathrm{h} \mathrm{wk} \mathrm{wk}^{-1}$ based on reported share of time spent by different members of the household on farm and off-farm activities). The share of irrigated land (ShIL) was introduced as an additional input that captured differences in land quality, and dummy variables (DZ3, DZ4, and DZ5) captured whether the farm was located in geographic zone 3,4 , or 5, respectively (zone 2 was the reference). Some crop producers had no animals; therefore, following Battese (1997), an additional dummy variable ( $\mathrm{Dav}=1$ if $\mathrm{AV}>0$ ) was used to avoid biased parameter estimates.

We specified a vector $z$ that included the following six categories of possible determinants of efficiency: (1) Three variables accounted for socioeconomic characteristics of the farm household. These were the age and education of the head of household (Age and $E d u$, both in years) and the size of the household ( $H S$, number of members). (2) One variable ( $S h O L$, share of farmed land owned by the household) reflected land tenure conditions. (3) One variable measured access to markets (Acc, the distance in $\mathrm{km}$ to the main road). (4) Eight variables captured management decisions. These included, in addition to the four input variables listed above $(L, W C, A V$, and $T)$, a dummy equal to one if the farmer had spent money on management training (e.g., attending a training course) or services (e.g., bookkeeping) in the course of the year (Dmanag). The dummy Dex was equal to one if the farmer had received assistance from extension services, and the dummy DVet was equal to one if the farmer had spent money on veterinary services. Finally, ShFI was defined as the share of farm income in total income. (5) Dindap was a dummy variable that was equal to one if the farm participated in any INDAP programs. (6) Finally, two variables measured various dimensions of a farm's access to credit. The first was total credit used (Cred) in millions of CLP. The second was a dummy that was equal to one if the head of the farm household was under credit constraint $(D c c)$.

On the other hand, possible endogeneity of the variables that measure credit access and technical efficiency was identified above as an important but seldom studied issue. We used the Durbin-Wu-Hausman test (Davidson and MacKinnon, 1993) to test endogeneity. First, we ran an auxiliary regression of the possibly endogenous variable on all other right-hand-side (RHS) variables of the original efficiency model plus a set of instrument variables. The instruments were chosen for being highly correlated with the possibly endogenous variable, but not with the term error of the original efficiency model. Second, we re-estimated the original model (Equation [3]) by including the residuals of the auxiliary regression as an additional RHS variable in the inefficiency model. Under the null hypothesis of no endogeneity, the coefficient on this additional residual term was equal to zero. If this null hypothesis were rejected (i.e., the coefficient on the auxiliary residuals differed significantly from zero), we re-estimated Equation [3] again by replacing the variable that had been found as endogenous with its fitted values from the auxiliary regression. This procedure was carried out for both the Cred (credit volume) and Dcc (credit constraint dummy) variables. The same instruments were used in both auxiliary regressions. These instruments included: the logarithm of on-farm income per hectare $(\ln (Y / L))$ as a proxy for household wealth, the quantity of owned land $(O L)$ as a proxy of a farmer's collateral. a dummy variable (Dporg) that was equal to 1 if the farmer was a member of a producers' organization as a proxy of social capital, and an indicator (Cworth) that ranked the lender's perception of the borrower's creditworthiness. This variable ranged from 1 (most) to 4 (least) and was calculated as the average of several subjective evaluations (each on a scale of 1 to 4 ) of the general cleanliness and orderliness of the household's dwelling and farm. This admittedly rough method of assessing creditworthiness is similar to the methods that Banco Estado has implemented in recent years in an attempt to reduce administrative costs in delivering small rural credits. There was also an indicator that ranks a farm's past repayment behavior for loans from INDAP (Repay). This variable was assigned values of 1,2 , and 3 where 1 is the best category and 3 the worst category.

Table 1 displays descriptive statistics for these variables in each of the two data subsets (crop producers and livestock producers) that are analyzed together with an indication of the expected influence of each variable on production and efficiency in Equation [3].

The study considered a sample of 342 specialized smallholder crop farms and 109 specialized smallholder 
Table 1. Definition and descriptive statistics of analysis variables.

\begin{tabular}{|c|c|c|c|c|c|c|c|c|c|c|}
\hline \multirow[b]{2}{*}{ Variable (description) } & \multirow[b]{2}{*}{ Units } & \multicolumn{4}{|c|}{ Crop producers $(n=342)$} & \multicolumn{4}{|c|}{ Livestock producers $(n=109)$} & \multirow{2}{*}{$\begin{array}{l}\text { Expected } \\
\text { sign }\end{array}$} \\
\hline & & Min & Mean & $\operatorname{Max}$ & SD & Min & Mean & Max & SD & \\
\hline \multicolumn{11}{|c|}{ Production function } \\
\hline $\mathrm{Y}$ (farm income) & thousands CLP & 100 & 2842 & 50400 & 5932 & 100 & 797 & 10600 & 1365 & + \\
\hline L (agricultural land used) & ha & 0.05 & 3.39 & 50.00 & 4.98 & 0.75 & 20.16 & 200.00 & 25.53 & + \\
\hline ShIL (share of irrigated land) & share & 0 & 0.66 & 1 & 0.45 & 0 & 0.20 & 1 & 0.37 & + \\
\hline WC (working capital) & thousands CLP & 40 & 2103 & 40000 & 4587 & 24 & 1365 & 9500 & 2104 & + \\
\hline $\mathrm{T}$ (labor input) & $\mathrm{h} w k^{-1}$ & 6.52 & 93.16 & 289.62 & 43.44 & 2.94 & 82.54 & 200.31 & 40.96 & + \\
\hline Av (value of livestock on farm) & thousands CLP & 0 & 184 & 1280 & 280 & 176 & 2299 & 16040 & 2166 & + \\
\hline $\operatorname{Dav}(=1$ if $\mathrm{Av}>0)$ & dummy & 0 & 0.43 & 1 & 0.49 & & & & & $?$ \\
\hline DZ3 (= 1 if farm in macro-zone 3 , reference is 2 ) & dummy & 0 & 0.47 & 1 & 0.49 & 0 & 0.06 & 1 & 0.24 & $?$ \\
\hline DZ4 (= 1 if farm in macro-zone 4 , reference is 2 ) & dummy & 0 & 0.19 & 1 & 0.39 & 0 & 0.23 & 1 & 0.42 & $?$ \\
\hline DZ5 (= 1 if farm in macro-zone 5 , reference is 2 ) & dummy & 0 & 0.09 & 1 & 0.29 & 0 & 0.56 & 1 & 0.49 & $?$ \\
\hline \multicolumn{11}{|c|}{ Determinants of inefficiency: Socioeconomic characteristics } \\
\hline HS (number of household members) & $\mathrm{nr}$ & 1 & 3.98 & 13 & 1.64 & 1 & 3.47 & 8 & 1.65 & - \\
\hline Age (age head of household) & $\mathrm{yr}$ & 24 & 51.10 & 84 & 13.62 & 31 & 53.30 & 86 & 12.57 & - \\
\hline Edu (years of education head of household ) & $\mathrm{yr}$ & 1 & 7.80 & 26 & 5.83 & 1 & 7.47 & 25 & 4.80 & - \\
\hline \multicolumn{11}{|c|}{ Determinants of inefficiency: Land tenure } \\
\hline ShOL (share of farmland that is owned) & share & 0 & 0.45 & 1 & 0.46 & 0 & 0.66 & 1 & 0.44 & - \\
\hline \multicolumn{11}{|c|}{ Determinants of inefficiency: Market access } \\
\hline Acc (distance to nearest main road) & $\mathrm{km}$ & 0 & 1.91 & 48.00 & 4.37 & 0 & 1.81 & 35.00 & 5.92 & + \\
\hline \multicolumn{11}{|c|}{ Determinants of inefficiency: Management } \\
\hline DVet (= 1 if farm spends on animal health) & dummy & 0 & 0.10 & 1 & 0.30 & 0 & 0.63 & 1 & 0.48 & - \\
\hline ShFI (share of farm income in total income) & share & 0.02 & 0.59 & 1 & 0.34 & 0.01 & 0.42 & 1 & 0.32 & - \\
\hline Dmanag (= 1 if farm spends on management) & dummy & 0 & 0.32 & 1 & 0.46 & 0 & 0.49 & 1 & 0.49 & - \\
\hline Dex (= 1 if farm receives extension services) & dummy & 0 & 0.15 & 1 & 0.36 & 0 & 0.22 & 1 & 0.42 & - \\
\hline \multicolumn{11}{|c|}{ Determinants of inefficiency: Public support } \\
\hline $\begin{array}{l}\text { Dindap (= } 1 \text { if farm gets any type of assistance } \\
\text { from INDAP) }\end{array}$ & dummy & 0 & 0.54 & 1 & 0.49 & 0 & 0.56 & 1 & 0.49 & - \\
\hline \multicolumn{11}{|c|}{ Determinants of inefficiency: Credit access } \\
\hline $\operatorname{Dcc}(=1$ if farmer feels credit constrained $)$ & dummy & 0 & 0.41 & 1 & 0.49 & 0 & 0.43 & 1 & 0.49 & $?$ \\
\hline Cred (total credit used) & thousands CLP & 0 & 0.43 & 24.00 & 1.70 & 0 & 0.14 & 4.00 & 0.45 & $?$ \\
\hline \multicolumn{11}{|c|}{ Instruments for endogeneity tests } \\
\hline $\ln (\mathrm{Y} / \mathrm{L})$ (on-farm income per hectare) & $\ln \left(\right.$ CLP ha $\left.^{-1}\right)$ & 3.17 & 6.22 & 9.55 & 0.99 & 1.05 & 3.59 & 6.50 & 1.15 & \\
\hline OL (quantity of own land) & ha & 0 & 3.02 & 35 & 5.36 & 0 & 13.64 & 110 & 19.99 & \\
\hline Dporg (= 1 if member of producers' organization) & dummy & 0 & 0.06 & 1 & 0.24 & 0 & 0.25 & 1 & 0.43 & \\
\hline Cworth (1 = most, 4 = least creditworthiness $)$ & category & 1 & 1.25 & 4 & 0.46 & 1 & 1.32 & 4 & 0.64 & \\
\hline Repay ( $1=$ best, $3=$ worst repayment history $)$ & category & 1 & 2.40 & 3 & 0.83 & 1 & 2.01 & 3 & 1.21 & \\
\hline
\end{tabular}

Source: Personal calculations using survey data.

$1 \mathrm{USD}=450$ CLP.

livestock farms, which was collected for INDAP in 2004. Maximum likelihood (ML) estimations of Equation [3] were performed in Ox (Doornik, 2002) with the SFAMB package (Stochastic Frontier Analysis using ModelBase). The one-step estimation procedure followed Battese and Coelli (1995). On-farm income and production input variables were divided by their arithmetic means so that parameter estimates could be directly interpreted as production elasticities evaluated at sample means. The hypothesis testing was carried out by likelihood ratio (LR) test and regularity conditions were tested (Salvanes and Tjøtta, 1998).

\section{RESULTS AND DISCUSSION}

\section{Specialized smallholder crop producers}

According to LR tests (Table 2), the best model for specialized crop producers does not include animal market value $(A V)$ and the corresponding dummy (Dav) in the production function as well as the share of own land farmed $(S h O L)$ in the inefficiency model. The first results suggest that either the capital stock does not play an important role in smallholder crop production in Chile, or the market value of animals is not an appropriate proxy for the relevant capital stock. The fact that $S h O L$ is not significant indicates that land tenure is not a determinant of technical efficiency for smallholders in Chile. Table 2 also shows that the Cobb Douglas restriction of the translog production function is rejected by the crop production data. The null hypothesis that there is no inefficiency in crop production $\left(u_{i}=0\right.$ for all farms $)$ is rejected $\left(\chi^{2}=69.4\right.$, critical value $=23.7)$, as well as the hypothesis that the variables in the vector $z$ make no significant contribution in explaining inefficiency $\left(\chi^{2}=57.0\right.$, critical value $\left.=22.4\right)$.

Estimates of Equation [3] for crop producers are presented in Table 3. The regional dummy variables have a significant impact and indicate, as expected, that crop production is lower, ceteris paribus, in Chile's southern regions. The partial elasticities of land, labor force, and working capital at sample mean levels are significant 


\begin{tabular}{|c|c|c|c|c|c|}
\hline Null hypothesis & $\begin{array}{c}\text { Log } \\
\text { likelihood }\end{array}$ & $\begin{array}{l}\text { Number of } \\
\text { model } \\
\text { parameters }\end{array}$ & $\begin{array}{l}\text { Number of } \\
\text { restrictions }\end{array}$ & $\begin{array}{l}\text { LR statistic } \\
\text { (critical value) }\end{array}$ & Decision \\
\hline Full model & -270.1 & 42 & - & - & - \\
\hline No animal market value (all terms involving $A V$ and $D_{a v}=0$ ) & -275.3 & 34 & 8 & $10.4(15.5)$ & Accept \\
\hline As above, and no effect of land tenure (the term involving $S h_{O L}=0$ ) ${ }^{*}$ & -275.5 & 33 & 1 & $0.4(3.8)$ & Accept \\
\hline As above, and no effect of credit markets (terms involving Cred and $D_{c c}=0$ ) & -281.1 & 31 & 2 & $11.2(6.0)$ & Reject \\
\hline Production function in Cobb Douglas (all cross-effect terms $=0$ ) & -294.1 & 23 & 10 & $37.2(18.3)$ & Reject \\
\hline No inefficiency $\left(\sigma_{0}\right.$ and all $\left.\phi_{j}=0\right)$ & -310.9 & 20 & 14 & $69.4(23.1)^{* * *}$ & Reject \\
\hline Variables in z do not explain inefficiency $\left(\right.$ all $\left.\phi_{j}=0\right)$ & -304.0 & 18 & 13 & $57.0(22.4)$ & Reject \\
\hline
\end{tabular}

*This model without animal market values and land tenure variable is the 'best model' against which ensuing hypotheses are tested.

***The likelihood ratio (LR) statistic follows an equally weighted mixture of a degenerate $\chi^{2}(0)$ and $\chi^{2}(1)$ distribution (Self and Liang, 1987). Kodde and Palm (1986) provide critical values.

with values of $0.33,0.37$, and 0.57 , respectively. Constant returns to scale are not rejected for crop production $\left(\chi^{2}\right.$ $=2.5$ compared with $5 \%$ critical value of 3.8 ). Results indicate that irrigated land is over seven times more productive than land without irrigation, and irrigation increases production elasticity of working capital from 0.57 to 0.69 (Battese et al., 1989).

Monotonicity in the variable input of land, labor, and working capital held for $100 \%$ of the observations in both the crop and livestock samples, while quasi-concavity held for $100 \%$ and $99 \%$ of the crop and livestock observations, respectively. An overview of the literature (Sauer et al., 2006; Zhu and Lansink, 2010; Xayavong et al., 2011) shows that regularity conditions are rarely fulfilled

Table 3. Stochastic production frontier results for specialized smallholder crop producers in Chile.

\begin{tabular}{|c|c|c|c|}
\hline & $\begin{array}{l}\text { Estimated } \\
\text { coefficient }\end{array}$ & $\begin{array}{c}\text { Robust standard } \\
\text { error }\end{array}$ & t-value \\
\hline Constant & -0.106789 & 0.1644 & -0.650 \\
\hline $\ln \mathrm{L}$ & 0.334082 & 0.1162 & $2.88^{* * *}$ \\
\hline $\ln \mathrm{WC}$ & 0.569556 & 0.09729 & $5.85^{* * *}$ \\
\hline $\ln \mathrm{T}$ & 0.365894 & 0.1334 & $2.74^{* * * *}$ \\
\hline ShIL & 2.12827 & 0.5455 & $3.90^{* * * *}$ \\
\hline DZ3 & -0.232518 & 0.08454 & $-2.75^{* * *}$ \\
\hline DZ4 & -0.494026 & 0.1119 & $-4.42^{* * *}$ \\
\hline DZ5 & -0.382536 & 0.1854 & $-2.06^{* *}$ \\
\hline $0.5 * \ln \mathrm{L}^{2}$ & -0.0950163 & 0.06836 & -1.39 \\
\hline $0.5 * \ln \mathrm{WC}^{2}$ & -0.0376718 & 0.04983 & -0.756 \\
\hline $0.5 * \ln \mathrm{T}^{2}$ & -0.104157 & 0.1105 & -0.942 \\
\hline $0.5 * \mathrm{ShIL}^{2}$ & -3.52445 & 0.9606 & $-3.67^{* * *}$ \\
\hline $\ln \mathrm{L} * \ln \mathrm{WC}$ & 0.105761 & 0.04814 & $2.20^{* * *}$ \\
\hline $\ln \mathrm{L} * \ln \mathrm{T}$ & -0.0146580 & 0.08097 & -0.181 \\
\hline $\ln \mathrm{L} * \mathrm{ShIL}$ & -0.0602729 & 0.1209 & -0.498 \\
\hline $\ln \mathrm{WC} * \ln \mathrm{T}$ & 0.139460 & 0.05394 & $2.59^{* * * *}$ \\
\hline $\ln \mathrm{WC} * \mathrm{ShIL}$ & 0.177708 & 0.08227 & $2.16^{* *}$ \\
\hline $\ln \mathrm{T} * \mathrm{ShIL}$ & -0.330413 & 0.1432 & $-2.31^{* *}$ \\
\hline $\ln (\sigma \mathrm{v})$ & -0.666436 & 0.04674 & $-14.3^{* * *}$ \\
\hline Constant & 3.36503 & 0.9897 & $3.40^{* * *}$ \\
\hline Age & 0.0128415 & 0.007147 & $1.80^{*}$ \\
\hline Edu & -0.102596 & 0.03805 & $-2.70^{* * * *}$ \\
\hline HS & -0.260360 & 0.1021 & $-2.55^{* *}$ \\
\hline Acc & -0.107182 & 0.04722 & $-2.27^{* *}$ \\
\hline $\ln \mathrm{L}$ & 0.523187 & 0.1897 & $2.76^{* * * *}$ \\
\hline $\ln \mathrm{WC}$ & 0.761701 & 0.2012 & $3.79^{* * *}$ \\
\hline $\ln \mathrm{T}$ & 0.523007 & 0.2367 & $2.21^{* * *}$ \\
\hline Dmanag & -0.0734015 & 0.2308 & -0.318 \\
\hline Dex & 1.09348 & 0.3987 & $2.74^{* * * *}$ \\
\hline ShFI & -7.13180 & 0.9562 & $-7.46^{* * *}$ \\
\hline Dindap & -0.332888 & 0.2523 & -1.32 \\
\hline Cred & -0.589365 & 0.1570 & $-3.75^{* * *}$ \\
\hline Dcc & 0.811282 & 0.2563 & $3.17^{* * * *}$ \\
\hline
\end{tabular}

globally in empirical work; however, because these were met by most of the observed data points in our samples, we concluded that the estimated production function was interpretable (Berndt and Christensen, 1973).

The estimated mean technical inefficiency in the sample of crop producers was $11 \%$. The distribution of inefficiency was correspondingly concentrated around farms with scores in the $90 \%$ to $100 \%$ range. The variables used to explain efficiency are jointly significant as illustrated above, and most of them are individually significant.

As expected, results indicated that there was a positive relationship between efficiency and the education of the head of household $(E d u)$, the age of the head of household $(A g e)$, family size $(H S)$, and the share of on-farm income in the total income $(S h F I)$. Technical efficiency decreased with increasing use of land, labor, and working capital $(L$, $T$, and $W C$ ). Extension services (Dex) and distance to main road are significant $(A c c)$, but their signs are unexpected. Thus, farmers who received extension and were located closer to the main road were less efficient. The latter result could be due to a conflation of the effects of market access and input use because more remote farms tended to be smaller and hence used fewer inputs. It might also be that distance from the main road was a poor measure of remoteness because a farm might be close to a main road but still quite far from relevant markets.

The variables that measured credit access have a significant impact on technical efficiency. The volume of credit (Cred) had a positive influence on technical efficiency, and farms that considered themselves credit constrained $(D c c)$ are significantly less efficient than others. The results in Table 3 can be used to demonstrate that the mean technical inefficiency of the credit-constrained crop farmers is $16 \%$, whereas it is $7 \%$ for unconstrained farmers. These results are in line with the free cash flow, credit evaluation, and embodied capital theories (Lambert and Bayda, 2005; Davidova and Latruffe, 2007; Onwuchekwa, 2008; Ziaul et al., 2011; Ayaz and Hussain, 2011) that explain a positive impact of credit on efficiency. Participation in INDAP programs (Dindap) has no significant impact on technical efficiency, and neither does the variable related to management efforts (Dmanag). 


\section{Specialized smallholder livestock producers}

The best model for the specialized livestock producers does not include the variables of land $(L)$, labor force $(T)$, and location $\left(D Z_{i}\right)$ in the production function (Table 4). However, the estimated coefficients of land and labor, while nonsignificant, have the expected positive signs. The estimates of these coefficients were 0.15 and 0.21 , respectively. The fact that land in the livestock production function is nonsignificant is no surprise and has been reported in several other empirical applications. Similarly, the land tenure variable $(S h O L)$ is nonsignificant in the inefficiency model for specialized livestock producers (Table 4).

As for crop production, the Cobb Douglas specification was rejected by the livestock production data. Constant returns to scale were rejected for specialized livestock production $\left(\chi^{2}=12.2\right.$, critical value $\left.=3.8\right)$. At sample means, returns to scale increased (1.35), which suggests that livestock producers in the sample were operating at a suboptimal size. This corresponds well to the discussion about the optimal size of cattle production that emerged in Chile in the last decade as a consequence of strong competition from imported meat from other MERCOSUR countries. According to Table 4 , the null hypothesis that there is no inefficiency in crop production $\left(u_{i}=0\right.$ for all farms $)$ is rejected $\left(\chi^{2}=44.1\right.$, critical value $\left.=23.1\right)$, as well as the hypothesis that the variables in the vector $z$ make no significant contribution in explaining inefficiency $\left(\chi^{2}=\right.$ 40.9 , critical value $=22.4$ ) .

The first three columns of Table 5 present the parameter estimates for the specialized livestock producers. The partial elasticities of working capital and animal market value evaluated at sample means are significant with values of 0.51 and 0.84 , respectively. The share of irrigated land (ShIL) is not significant, which is not surprising for livestock production. However, the coefficient on the interaction term between ShIL and the working capital input $(\log \mathrm{WC} * \mathrm{ShIL})$ is significant. As a result, production elasticity of working capital is slightly higher on irrigated than non-irrigated land $(0.55$ and 0.51 , respectively).

The mean inefficiency was $22 \%$ in the sample of specialized livestock producers. Most of the variables used to explain efficiency in specialized livestock production are significant. As for crop production, technical efficiency of specialized livestock production increased with the age and education of the head of household, and with the increasing share of on-farm income in total income.

The hypothesis that the credit variables are jointly nonsignificant is rejected (Table 4). Inefficiency increased with increasing volume of credit (Cred), which supports the agency cost and adjustment theories in results obtained by other studies (Hadley et al., 2001; Karagiannis and Sarris, 2005; Hadley, 2006; Davidova and Latruffe, 2007) and is lower for farms that perceive themselves as credit constrained (Dcc) (Table 5). In other words, given two identical farms with equal credit volumes, the one that is credit constrained will be more efficient; given two identical farms that are both credit constrained, the one with a larger credit volume will be less efficient. These results support the agency cost and adjustment theories outlined above. They might also reflect longer gestation periods for investments in livestock production (e.g., breeding) and possible temporary reductions in efficiency that occur while farmers are learning to implement new technologies.

Receiving support from INDAP increased the technical efficiency of specialized livestock farms. This effect was nonsignificant for specialized crop production. This implies that special efforts to support livestock production would have an important impact. A surprising result is that farmers who reported spending money on management training and services (Dmanage $=1$ ) are significantly less efficient than those who do not.

\section{Endogeneity of credit variables}

We estimated a Tobit auxiliary regression for the credit volume variable (Cred) and a Probit auxiliary regression for the credit constraint variable $(D c c)$. The resulting residuals were added to the RHS of Equation [3]. For crop production we found that the null hypothesis that these residuals are jointly nonsignificant was not rejected $\left(\chi^{2}=1.4\right.$, critical value $\left.=5.99\right)$. However, for livestock production this null hypothesis was rejected $\left(\chi^{2}=13.2\right.$, critical value $=5.99)$, indicating that the credit variables are endogenous.

Table 4. Likelihood ratio (LR) tests for livestock production frontier model.

\begin{tabular}{|c|c|c|c|c|c|}
\hline Null hypothesis & $\begin{array}{c}\log \\
\text { likelihood }\end{array}$ & $\begin{array}{l}\text { Number of } \\
\text { model } \\
\text { parameters }\end{array}$ & $\begin{array}{l}\text { Number of } \\
\text { restrictions }\end{array}$ & $\begin{array}{l}\text { LR statistic } \\
\text { (critical value) }\end{array}$ & Decision \\
\hline Full model & -54.0 & 42 & & & \\
\hline No labor and land inputs, no regional dummies (all terms involving $L, T$ and $D Z_{i}=0$ ) & -65.2 & 26 & 16 & $22.4(26.3)$ & Accept \\
\hline As above, and no effect of land tenure (the term involving $S h_{O L}=0$ ) ${ }^{*}$ & -65.6 & 25 & 1 & $0.9(3.8)$ & Accept \\
\hline No effect of credit markets (terms involving Cred and $D_{c c}=0$ ) & -70.4 & 23 & 2 & $9.7(6.0)$ & Reject \\
\hline Production function in Cobb Douglas (all cross-effect terms $=0$ ) & -78.1 & 19 & 6 & $25.0(12.6)$ & Reject \\
\hline No inefficiency $\left(\sigma_{0}\right.$ and all $\left.\phi_{j}=0\right)$ & -87.6 & 10 & 14 & $44.1(23.1)^{* *}$ & Reject \\
\hline Variables in $\mathrm{z}$ do not explain inefficiency $\left(\right.$ all $\phi_{j}=0$ ) & -86.0 & 12 & 13 & $40.9(22.4)$ & Reject \\
\hline
\end{tabular}

"This model without land and labor inputs, regional dummies, and land tenure variable is the 'best model' against which the ensuing hypotheses are tested.

${ }^{* *}$ The LR statistic follows an equally weighted mixture of a degenerate $\chi^{2}(0)$ and $\chi^{2}(1)$ distribution (Self and Liang, 1987). Kodde and Palm (1986) provide critical values. 
Table 5. Stochastic production frontier results for specialized smallholder livestock producers in Chile.

\begin{tabular}{|c|c|c|c|c|c|c|}
\hline \multirow{2}{*}{$\begin{array}{l}\text { Explanatory } \\
\text { variable }\end{array}$} & \multicolumn{3}{|c|}{ Initial model } & \multicolumn{3}{|c|}{$\begin{array}{l}\text { Model corrected for endogeneity (Cred and Dcc replaced } \\
\text { by fitted values from Tobit and Probit regressions, } \\
\text { respectively) }\end{array}$} \\
\hline & Coefficient & Robust-SE & t-Value & Coefficient & Robust-SE & t-Value \\
\hline Constant & 0.120706 & 0.09003 & 1.34 & 0.0272459 & 0.09797 & 0.278 \\
\hline $\ln \mathrm{WC}$ & 0.515159 & 0.07797 & $6.61^{* * * *}$ & 0.426588 & 0.06878 & $6.20^{* * *}$ \\
\hline $\ln \mathrm{AV}$ & 0.848737 & 0.1260 & $6.74^{* * *}$ & 0.983599 & 0.1158 & $8.494^{* * * *}$ \\
\hline ShIL & -0.186906 & 0.9893 & -0.189 & 0.142860 & 0.9394 & 0.152 \\
\hline $0.5 * \ln \mathrm{WC}^{2}$ & 0.0862700 & 0.04604 & $1.87^{*}$ & 0.0333192 & 0.04723 & 0.705 \\
\hline $0.5 * \ln \mathrm{AV}^{2}$ & 0.292464 & 0.1115 & $2.62^{* * *}$ & 0.267871 & 0.1206 & $2.22^{* *}$ \\
\hline $0.5 * \mathrm{ShIL}^{2}$ & 0.632623 & 2.038 & 0.310 & -0.236044 & 1.958 & -0.121 \\
\hline $\ln \mathrm{WC} * \ln \mathrm{AV}$ & 0.0491570 & 0.05583 & 0.881 & 0.117587 & 0.06273 & $1.87^{*}$ \\
\hline $\ln \mathrm{WC} * \mathrm{ShIL}$ & 0.164866 & 0.07960 & $2.07^{* *}$ & 0.115614 & 0.08792 & 1.31 \\
\hline $\ln \mathrm{AV} * \mathrm{ShIL}$ & -0.241431 & 0.2174 & -1.11 & -0.0959073 & 0.1746 & -0.549 \\
\hline $\ln \left(\sigma_{\mathrm{v}}\right)$ & -1.01001 & 0.07892 & $-12.8^{* * *}$ & -0.944463 & 0.07208 & $13.1^{* * * *}$ \\
\hline Constant & 1.62014 & 0.9506 & $1.70^{*}$ & 532.271 & 2.422 & $2.20^{* * *}$ \\
\hline Age & -0.0224766 & 0.01133 & $-1.98^{*}$ & -0.0501869 & 0.02235 & $-2.25^{* *}$ \\
\hline Edu & -0.0275811 & 0.02553 & -1.08 & -0.0411886 & 0.03476 & -1.19 \\
\hline HS & 0.0543054 & 0.1338 & 0.406 & 0.213059 & 0.1854 & 1.15 \\
\hline Acc & -0.0423551 & 0.03836 & -1.10 & 0.0109975 & 0.05678 & 0.194 \\
\hline $\ln \mathrm{WC}$ & 0.394800 & 0.1762 & $2.24^{* *}$ & 0.0185190 & 0.2032 & 0.0911 \\
\hline $\ln \mathrm{AV}$ & 0.664256 & 0.2607 & $2.55^{* *}$ & 1.53111 & 0.6873 & $2.23^{* *}$ \\
\hline Dmanag & 0.870980 & 0.2725 & $3.20^{* * * *}$ & 2.46691 & 0.9277 & $2.66^{* * *}$ \\
\hline Dindap & -0.728415 & 0.2543 & $-2.86^{* * *}$ & -1.84552 & 0.6715 & $-2.75^{* * *}$ \\
\hline Dex & 0.345449 & 0.2695 & 1.28 & -0.530131 & 0.6291 & -0.843 \\
\hline Dvet & -0.145365 & 0.2782 & -0.523 & 0.00333596 & 0.3461 & 0.00964 \\
\hline ShFI & -2.09851 & 0.7935 & $-2.64^{* * *}$ & -3.81807 & 1.411 & $-2.78^{* * * *}$ \\
\hline Cred & 0.236765 & 0.1147 & $2.06^{* *}$ & 0.990220 & 0.4682 & $2.11^{* *}$ \\
\hline Dcc & -1.10540 & 0.3468 & $-3.19^{* * *}$ & -5.62721 & 2.248 & $-2.50^{* * *}$ \\
\hline
\end{tabular}

${ }^{* * *},{ }^{* *},{ }^{*}$ : Significant at the $1 \%, 5 \%$, and $10 \%$ probability levels, respectively.

This difference in the results between crop and livestock production could be explained by the credit evaluation theory, which provides a plausible explanation for causality from technical efficiency to credit access because lenders can partly base their credit evaluations on a firm's performance; this could mean a positive correlation between credit and technical efficiency because inefficient firms are less likely to receive credit. In the sample of analyzed farms, the main lenders are INDAP and Banco Estado, two institutions with a long tradition of providing support to smallholders. These institutions supported the creation of information centers for livestock producers in Chile's southern regions where production was concentrated at the beginning of the last decade. These centers, for which there is no equivalent for crop production, served as forums to exchange information on market perspectives and "who is who" in terms of productivity, cost, and reputation. The endogeneity of credit access by livestock producers might reflect the knowledge about farms by lenders, knowledge that has improved and is more readily available as a result of the information centers.

The final three columns of Table 5 present corrected estimates of Equation [3] for livestock production using the fitted values of the auxiliary Tobit and Probit models as instruments for Cred and Dcc. Comparing the estimated coefficients with and without the correction for endogeneity reveals few major changes. Most coefficients retain their original signs, magnitudes, and levels of significance. The coefficients of credit access variables Cred and Dcc are important exceptions to this rule because they increase by factors of approximately 4 and 5, respectively. This indicates that the failure to account for endogeneity leads to considerable underestimation of the (negative) impact of credit access on technical efficiency in specialized smallholder livestock production in Chile.

\section{CONCLUSIONS}

By using a parametric approach, we estimated stochastic production functions for 109 specialized smallholder livestock and 342 specialized smallholder crop producers in Chile. Results for crop producers indicate that credit volume has a positive impact on efficiency, thus supporting the free cash flow, credit evaluation, and embodied capital theories that have been proposed in the literature. In livestock production, credit volume had a negative impact on efficiency, which supports the agency cost and adjustment theories. Additionally, we found that credit-constrained farmers are less efficient in crop production and more efficient in livestock production.

We checked the possibility of simultaneity between technical efficiency and variables related to the credit market in our results; the hypothesis of no simultaneity in crop production could not be rejected, but it could be rejected in livestock production, suggesting any kind of feedback from the levels of efficiency to the variables related to the credit market. We justify this finding from an 
institutional perspective; lenders have more information and knowledge of livestock producers. Finally, correcting endogeneity does not lead to qualitatively different results, but it does influence point estimates of parameters in the production function and inefficiency models. This highlights the importance of testing for endogeneity in the variables used to model inefficiency effects.

\section{ACKNOWLEDGEMENTS}

Both authors gratefully acknowledge the support and suggestions received from Bernhard Brümmer and the National Congress XVIII of Agricultural Economists, Termas de Chillán, Chile, 17-18 October 2013.

\section{LITERATURE CITED}

Ayaz, S., and Z. Hussain. 2011. Impact of institutional credit on production efficiency of farming sector: A case study of District Faisalabad. Pakistan. Economic and Social Review 49:149-162.

Battese, G. 1997. A note on the estimation of Cobb-Douglas production functions when some explanatory variables have cero values. Journal of Agricultural Economics 48:250-252.

Battese, G.E., and T.J. Coelli. 1995. A model for technical inefficiency effects in a stochastic frontier production function for panel data. Empirical Economics 20:325-332.

Battese, G., T. Coelli, and T. Colby. 1989. Estimation of frontier production functions and the efficiencies of Indian farms using panel data from ICRISTAT's village level studies. Journal of Quantitative Economics 5:327-348.

Berndt, E., and L. Christensen. 1973. The translog function and the substitution of equipment, structures and labour in U. S. manufacturing 1929-1968. Journal of Econometrics 1:81-114.

Binam, J.N., J. Tonyé, N. Wandji, G. Nyambi, and M Akoa. 2004. Factors affecting the technical efficiency among smallholder farmers in the slash and burn agriculture zone of Cameroon. Food Policy 29:531-545.

Brümmer, B., and J. Loy. 2000. The technical efficiency impact of farm credit programs: A case study of northern Germany. Journal of Agricultural Economics 51:405-418.

Caudill, S.B., and J.M. Ford. 1993. Biases in frontier estimation due to heteroscedasticity. Economics Letters 41:17-20.

Caudill, S.B., J.M. Ford, and D.M. Gropper. 1995. Frontier estimation and firm-specific inefficiency measures in the presence of heteroscedasticity. Journal of Business and Economic Statistics 13:105-111.

Davidova, S., and L. Latruffe. 2007. Relationships between technical efficiency and financial management for Czech Republic farms. Journal of Agricultural Economics 58:269-288.

Davidson, R., and J. MacKinnon. 1993. Estimation and inference in econometrics. 896 p. Oxford University Press, New York, USA.
Doornik, J.A. 2002. Object-oriented programming in econometrics and statistics using Ox: A Comparison with $\mathrm{C}++$, Java and C\#. p. 115-147. In S.S. Nielsen (ed.) Programming languages and systems in computational economics and finance. Kluwer Academic Publishers, Dordrecht, The Netherlands.

Griliches, Z. 1963. Estimation of the aggregate production function from cross sectional data. Journal of Farm Economics 45:419-428

Hadley, D. 2006. Patterns in technical efficiency and technical change at the Farm-level in England and Wales, 1982-2002. Journal of Agricultural Economics 57(1):81-100.

Hadley, D., B. Sankar, C. Thirtle, and T. Coelli. 2001. Financial exposure and farm efficiency: Evidence from the England and Wales dairy sector. Annual Meetings of the American Agricultural Economics Association (AAEA), Chicago, Illinois. 5-8 August. AAEA, Milwaukee, Wisconsin, USA.

Huang, C., and J. Liu. 1994. Estimation of a non-neutral stochastic frontier production function. The Journal of Productivity Analysis 5:171-180.

Karagiannis, G., and A. Sarris. 2005. Measuring and explaining scale efficiency with the parametric approach: The case of Greek tobacco growers. Agricultural Economics 33:441-451.

Kodde, D., and F. Palm. 1986. Wald criteria for jointly testing equality and inequality restrictions. Econometrica 54:1243-1248.

Lambert, D., and V. Bayda. 2005. The impacts of farm financial structure on production efficiency. Journal of Agricultural and Applied Economics 37:277-289.

Nasr, R.E., P. Barry, and P. Ellinger. 1998. Financial structure and efficiency of grain farms. Agricultural Finance Review 58:33-48.

Onwuchekwa, I. 2008. Technical efficiency of cassava farmers in South Eastern Nigeria: Stochastic Frontier Approach. Agricultural Journal 3(2):152-156.

Salvanes, K., and S. Tjøtta. 1998. A note on the importance of testing for regularities for estimated flexible functional forms. Journal of Productivity Analysis 9:133-143.

Sauer, J., K. Frohberg, and H. Hockman. 2006. Stochastic efficiency measurement: The course of theoretical consistency. Journal of Applied Economics 9:139-165.

Self, S., and K.Y. Liang. 1987. Asymptotic properties of maximum likelihood estimators and likelihood ratio tests under nonstandard conditions. Journal of the American Statistical Association 82:605-610.

Wang, H-J., and P. Schmidt. 2002. One-step and two-step estimation of the effects of exogenous variables on technical efficiency levels. Journal of Productivity Analysis 18(2):129-144.

Xayavong, V., N. Islam, and R. Salim. 2011. Estimating production response of broadacre farms in Western Australia: The nexus of empirics and economics revisited. Economic Analysis and Policy 41(3):217-232.

Zellner, A., J. Kmenta, and J. Dreze. 1966. Specification and estimation of Cobb-Douglas production function models. Econometrica 34:784-795.

Zhu, X., and O. Lansink. 2010. Impact of CAP subsidies on technical efficiency of crop farms in Germany, The Netherlands and Sweden. Journal of Agricultural Economics 61(3):545-564.

Ziaul, M., M. Shakil, and A. Mallick. 2011. Technical efficiency of agricultural farms in Khulna, Bangladesh: Stochastic Frontier Approach. International Journal of Economics and Finance $3(3): 248-256$. 